\title{
Surgical Management of Adult Diaphragmatic Hernia - An Institutional Experience
}

\author{
Kunduru Navakishore ${ }^{1}$, Digvijoy Sharma ${ }^{2}$, Gangadhar Rao Gondu ${ }^{3}$, Venu Madhav Thumma ${ }^{4}$, Suryaramachandra \\ Varma Gunturi', Jagan Mohan Reddy ${ }^{6}$, Nagari Bheerappa ${ }^{7}$
}

${ }^{1}$ Assistant Professor, ${ }^{2}$ Senior Resident, ${ }^{3}$ Senior Resident, ${ }^{4}$ Associate Professor, ${ }^{5}$ Associate Professor, ${ }^{6}$ Assistant Professor, ${ }^{7}$ Professor and Head, Department of Surgical Gastroenterology, Nizam's Institute of Medical Sciences, Hyderabad, India

Corresponding author: Digvijoy Sharma, Department of Surgical gastroenterology, Speciality Block, 5th Floor, Nizam's Institute of Medical Sciences, Punjagutta, Hyderabad-500082, India

DOI: 10.21276/ijcmsr.2018.3.2.13

How to cite this article: Kunduru Navakishore, Digvijoy Sharma, Gangadhar Rao Gondu, Venu Madhav Thumma, Suryaramachandra Varma Gunturi, Jagan Mohan Reddy, Nagari Bheerappa. Surgical management of adult diaphragmatic hernia - an instituitional experience. International Journal of Contemporary Medicine Surgery and Radiology. 2018;3(2):B54-B57.

\section{A B S T R A C T}

Introduction: Congenital diaphragmatic hernia usually occurs in childhood. Presentation in adulthood is extremely rare. Surgical repair has been associated with low morbidity and mortality and excellent long term outcomes with low rate of recurrence. Here we present our experience of surgical management of diaphragmatic hernia over the last 10 years.

Material and Methods: Records of 40 patients who underwent surgery for adult diaphragmatic hernia between January 2007 to December 2017, were reviewed retrospectively.

Results: Median age of presentation was 38 (18-71) years with a male female ratio of 1.6:1. The most common symptom was breathlessness, followed by chest discomfort. Laparotomy and mesh repair was the most commonly performed procedure followed by anatomical repair. No recurrence was reported during the follow-up period ranging from 3 months to 7 years.

Conclusion: Congenital diaphragmatic hernia is a rare surgical condition primarily diagnosed in infants and seen rarely in adults. Surgical repair has been associated with low morbidity and mortality and excellent long term outcomes with low rate of recurrence.

Keywords: Congenital Diaphragmatic Hernia, Adulthood Presentation, Surgical Repair

\section{INTRODUCTION}

Congenital diaphragmatic hernia $(\mathrm{CDH})$ usually occurs in childhood. Presentation in adulthood is extremely rare. The pathogenesis is due to failure of the development of muscular diaphragm, which leads to herniation of abdominal viscera into thoracic cavity. It is diagnosed on the basis of clinical features and imaging characterstics on chest radiograph and computed tomography scans.

The types of $\mathrm{CDH}$ described are: posterolateral hernia of Bochdalek, parasternal hernia of Morgagni-Larrey, eventration of diaphragm, and peritoneal-pericardial hernia. Among these, Bochdalek hernia is the most common type which was first described by Bochdalek in $1848 .{ }^{1}$ Pathogenesis involves failure of closure of pleuroperitoneal canal, during embryogenesis. Left sided $\mathrm{CDH}$ are more common $(85 \%)$ as the left canal closes later than the right. ${ }^{2}$ Eventration of the diaphragm occurs due to failure of development of part or whole of muscular hemidiaphragm. ${ }^{3}$ Clinically, it is characterized by abnormal elevation of hemidiaphragm due to paralysis, aplasia, or atrophy of muscle fibers. ${ }^{4}$ Complete eventration almost exclusively occurs on the left side. ${ }^{5,6}$ In symptomatic patients, surgical repair is the treatment of choice with low morbidity and mortality.
The rate of recurrence is low with good long-term outcomes. Here we present our experience of surgical management of diaphragmatic hernia over last 10 years.

\section{MATERIAL AND METHODS}

The present study was a retrospective analysis of our experience of surgical management of $\mathrm{CDH}$ over last ten years. A total of 40 patients with $\mathrm{CDH}$ were included.

After permission from Institutional Ethical Committee and Review Board, records of patients who underwent surgical management of diaphragmatic hernia between January 2007 and December 2017 at our institute, were reviewed retrospectively. Patients of age 18 years and above who underwent surgical treatment only, were included in the study. Traumatic diaphragmatic hernias were excluded. Patient records were reviewed for demographic characteristics, clinical presentation, radiological findings, past and present surgical details and outcome of surgery in terms of morbidity and mortality. Meshplasty was the preferred surgical procedure and primary repair was done for smaller defects $(<10 \mathrm{cms})$. Postoperative complications and morbidity were recorded. Follow-up was done on outpatient basis. Patients were screened for recurrence by chest radiograph and ultrasound chest. 


\section{STATISTICAL ANALYSIS}

The results are reported as median with range, and percentage. All analysis were done with the help of microsoft office 2007.

\section{RESULTS}

A total of 40 patients were included in the study. The median age of presentation was 38 years (18-71 years). There were 25 males and 15 females in the study.(Table 1 ) The most common symptom was shortness of breath (60\%), followed by chest pain and discomfort (50\%) and abdominal pain (40\%). Incidental detection was present in 4 patients (Table2). The median duration of symptoms was 28 months (12-120 months). Twenty five patients had left sided hernia (Bochdalek) and rest 5 had right sided hernia (Morgagni). Ten patients had eventration of diaphragm. Three patients had associated gastric volvulus. One patient had recurrent hernia after 5years of initial repair.

Routine blood and coagulation parameters were within normal limits in all patients. Diagnosis of diaphragmatic hernia was confirmed with MDCT thorax in all cases (figure $1,2)$. Twenty one patients underwent open mesh repair of the hernia defect and for 4 patients primary repair was done in view of smaller defect $(<10 \mathrm{~cm}$ ) (figure 3,5$)$ Eight patients with diaphragmatic eventration underwent plication. 3 patients had associated gastric volvulus for which anterior gastropexy was done along with mesh repair of hernia (figure 4) Laparoscopic repair and plication was done in 3 patients. One patient had recurrent left sided diaphragmatic hernia for which mesh repair was done. There was one mortality due

Table 1: Demographic profile of patients.

\begin{tabular}{|l|l|}
\hline Total number of cases & 40 \\
\hline Range of age & $18-71$ years \\
\hline Sex & M:F- 25:15 \\
\hline Bochdalek hernia & 25 \\
\hline Morgagni hernia & 5 \\
\hline Diaphragmatic eventration & 10 \\
\hline Associated Gastric volvulus & 3 \\
\hline
\end{tabular}

Table 2- Clinical features

\begin{tabular}{|l|l|l|}
\hline Symptoms & Number & Percentage (\%) \\
\hline Shortness of breath & 24 & 60 \\
\hline Chest discomfort & 20 & 50 \\
\hline Abdominal pain & 16 & 40 \\
\hline Vomiting & 3 & 7.5 \\
\hline Incidental & 4 & 10 \\
\hline
\end{tabular}

Table 3- Procedure and complications

\begin{tabular}{|l|l|}
\hline Surgical procedure & Number of cases(total-40) \\
\hline Laparotomy and mesh repair & 22 \\
\hline Laparotomy and anatomical repair & 4 \\
\hline $\begin{array}{l}\text { Mesh repair with anterior } \\
\text { gastropexy }\end{array}$ & 3 \\
\hline Laparoscopic repair & 3 \\
\hline Laparotomy and plication & 8 \\
\hline \hline Complication & Number \\
\hline ARDS and mortality & 1 \\
\hline $\begin{array}{l}\text { Abdominal compartment } \\
\text { syndrome }\end{array}$ & 1 \\
\hline Prolonged ventilator support & 2 \\
\hline
\end{tabular}

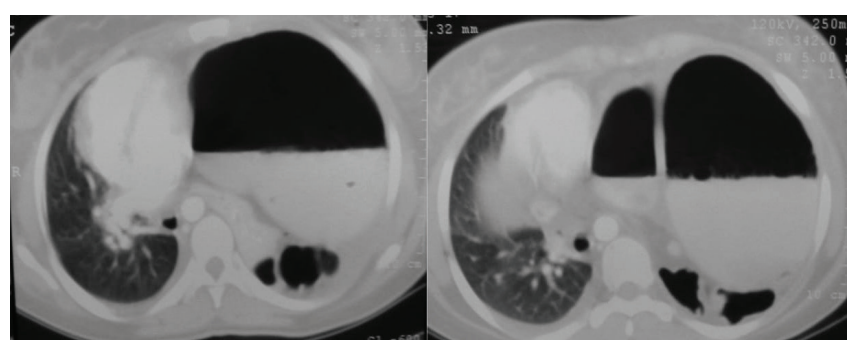

Figure-1: Bochdalek hernia with stomach volvulus

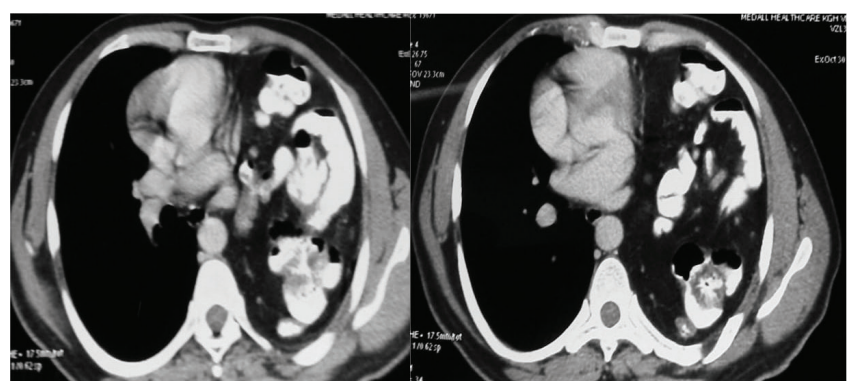

Figure-2: Bochdalek, hernia with small bowel herniation into left thorax

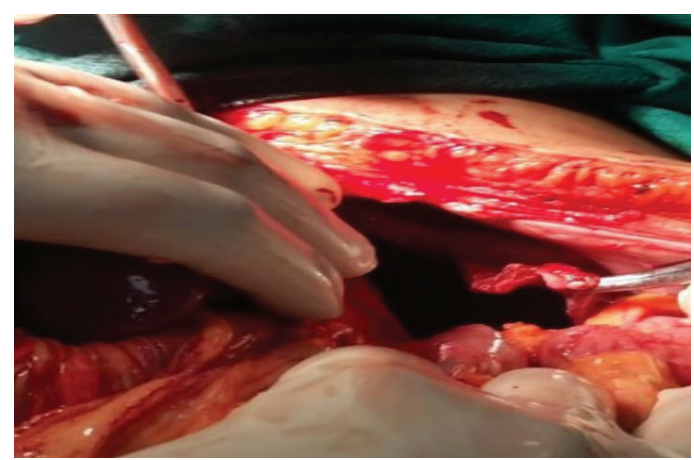

Figure-3: Intraoperative image of left sided diaphragmatic henia defect

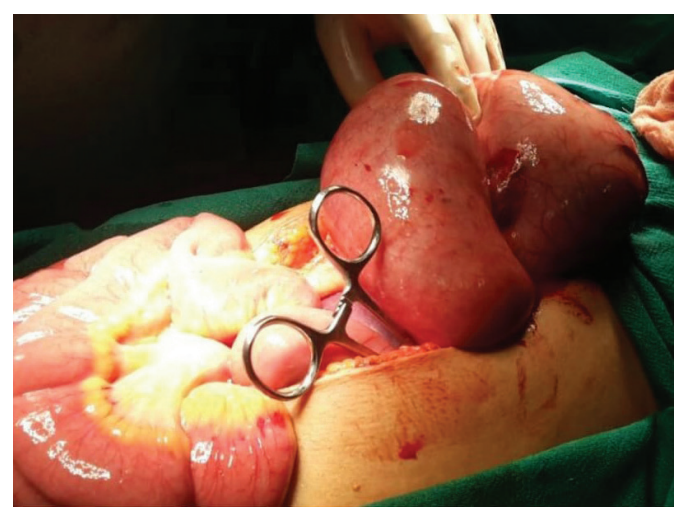

Figure-4: Gastric volvulus associated with Bochdalek hernia

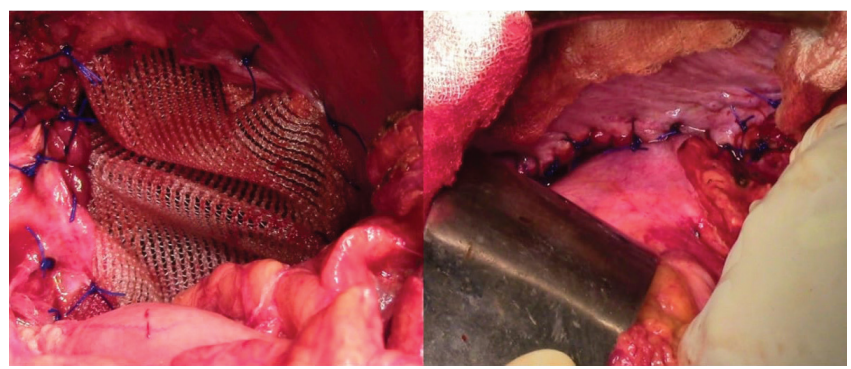

Figure-5: Meshplasty and anatomical repair 
to acute respiratory distress syndrome and respiratory failure. One patient had abdominal compartment syndrome postoperatively and was re-explored and laparostomy was done. 2 patients required prolonged ventilator support and were eventually weaned off and discharged in stable condition (Table 3). None of the patients had recurrence during a median follow-up of 24 months.

\section{DISCUSSION}

Congenital diaphragmatic hernia $(\mathrm{CDH})$ presents in different ways in adults and pediatric age group. Cyanosis and respiratory distress are predominant features in neonates and infancy, while in adults it presents with chest pain, difficulty in breathing, abdominal pain and sometimes intestinal obstruction. ${ }^{7}$ Some cases may remain asymptomatic and it may be due to the occlusion of diaphragmatic defect by the intra-abdominal viscus. ${ }^{8}$ Majority of right sided $\mathrm{CDH}$ are asymptomatic because liver prevents herniation of other organs. $^{9}$

In congenital diaphragmatic hernia various intra-abdominal organs can herniate into the thorax. Organs that commonly herniate are stomach, ileum, colon, and spleen and on the right side liver and right kidney may also herniate along with the bowel loops. Bochdalek hernia can be associated with lung hypoplasia, malrotation of midgut, and cardiac defects, whereas Morgagni's hernia may be associated with hypoplasia of the right lobe of liver. ${ }^{10}$ Bochdalek hernia is a rare hernia in adults, so misdiagnosis is common. Strangulation of herniated bowel can occur due to missed or delayed diagnosis. ${ }^{11} \mathrm{CT}$ scan is imaging of choice for the diagnosis and evaluation of the hernia contents, especially when the defect is small. ${ }^{12,13}$ About 38\% of these cases are misdiagnosed as pleural effusion, empyema, lung cyst, and pneumothorax when CT scan is not done. ${ }^{14} \mathrm{MRI}$ is an alternative diagnostic modality.

All diaphragmatic hernias should be repaired at the time of diagnosis, given the risk of intestinal obstruction and strangulation. Traditionally, $\mathrm{CDH}$ have been repaired via laparotomy or thoracotomy. Minimally invasive approaches may also

provide excellent visualisation for repair and may have additional benefits, such as decreased pain, shorter hospitalization and improved cosmesis. ${ }^{15,16}$ Primary closure with interrupted, non absorbable suture is the preferred method of repair, when the diaphragmatic edges can be apposed without undue tension. The use of mesh has been recommended When the size of the diaphragmatic defect exceeds 20 to $30 \mathrm{~cm}^{17,18}$ (figure-5). Recurrence rates are low for all approaches (laparotomy, thoracotomy, laparoscopy, and thoracoscopy and outcomes have been excellent. ${ }^{19}$

\section{CONCLUSION}

Congenital diaphragmatic hernia is a rare surgical condition primarily diagnosed in infants and seen rarely in adults. Adult forms of $\mathrm{CDH}$ can be identified incidentally or as a part of investigations for nonspecific gastrointestinal or respiratory symptoms. All adult $\mathrm{CDH}$ patients should undergo surgical repair to prevent complications like incarceration and strangulation of abdominal viscera leading to increased morbidity and mortality. There is enough literature demonstrating the safety and efficacy of using open or minimally invasive repair techniques. Irrespective of the approach selected, surgical repair is the treatment of choice with low morbidity and mortality. The rate of recurrence is low with good long-term outcomes.

\section{REFERENCES}

1. Bochdalek VA. Einige Betrachtungen über die Entstehung des angeborenen Zwerchfellbruches. Als Beitrag zur Anatomie der Hernien. Vierteljahrschrift prakt Heilunde. 1848;5(1):89-97.

2. L. A. Christiansen, M. Blichert-Toft, and S. Bertelsen. Strangulated diaphragmatic hernia. A clinical study. The American Journal of Surgery 1975; 129(2): 574-578.

3. R. Prasad, J. Nath, and P. K. Mukerji. Eventration of diaphragm. Journal of the Indian Medical Association 1986;84(6):187-189.

4. B. K. P. Goh, M. C. C. Teo, S.-P. Chng, and K.-C. Soo. Right sided Bochdalek's hernia in an adult. American Journal of Surgery 2007; 194(3):390-391.

5. T. V. Thomas. Congenital eventration of the diaphragm. The Annals of Thoracic Surgery 1970; 10(2):180-192.

6. M. Al-Emadi, H. Ismail, M. A. Nada, and H. Al-Jaber. Laparoscopic repair of bochdalek hernia in an adult. SurgicalLaparoscopy and Endoscopy 1999;9(6):423425.

7. A. Alam and B. N. Chander. Adult Bochdalek hernia. Medical Journal Armed Forces India 2005;61(3):284286.

8. S. Nitecki and J. A. Bar-Maor. Late presentation of Bochdalekhernia: our experience and review of the literature. Israel Journal of Medical Sciences 1992;28(89):711-714.

9. M. E.Mullins, J. Stein, S. S. Saini, and P. R. Mueller. Prevalence of incidental Bochdalek's hernia in a large adult population. American Journal of Roentgenology 2001;177(2):363-366.

10. R. Marleta. Diaphragmatic anomalies. in Swenson's Textbookof Paediatric Surgery, J. G. Raffensperger, Ed., pp. 721-735, Appleton and Lange, New York, NY, USA, 5th edition, 1990.

11. E. S. Dhaka, M. I. Hasan, K. K. Mutatkar, and M. L. Sapra. Strangulated diaphragmatic hernia simulating hydropneumothorax (case report). The Journal of the Association of Physicians of India 1979;27(8);777-779.

12. M. S. Shin, S. A. Mulligan, W. A. Baxley, and K.-J. Ho. Bochdalek hernia of diaphragm in the adult: diagnosis by computed tomography. Chest 1987;92(6):10981101.

13. A. C. Wilbur, A. Gorodetsky, and J. F. Hibbeln. Imaging findings of adult bochdalek hernias. Clinical Imaging, 1994;18(3):224-229.

14. S. Thomas and B. Kapur. Adult Bochdalek herniaclinical features, management and results of treatment. The Japanese Journal of Surgery 1991;21(1):114-119.

15. Palanivelu C, Rangarajan M, Senthilkumar R, et al. Laparoscopic surgery for giant adult Bochdalek diaphragmatichernia: combined suturing and polypropylene mesh repair. J Coll Physicians Surg Pak 2007;17(8):502-4. 
16. Yamaguchi M, Kuwano $H$, Hashizume $M$, et al. Thoracoscopictreatment of Bochdalek hernia in theadult: report of a case. Ann Thorac Cardiovasc Surg 2002;8(2):106-8.

17. Palanivelu C, Rangarajan M, Rajapandian S, et al. Laparoscopic repair of adult diaphragmatic herniasand eventration with primary sutured closure andprosthetic reinforcement: a retrospective study. Surg Endosc 2009;23(5):978-85.

18. Kitano Y, Lally KP, Lally PA. Late-presenting congenitaldiaphragmatic hernia. J PediatrSurg 2005;40(12):1839-43.

19. Horton JD, Hofmann LJ, Hetz SP. Presentation and management of Morgagni hernias in adults: a review of 298 cases. Surg Endosc 2008;22(6):1413-20.

Source of Support: Nil; Conflict of Interest: None

Submitted: 18-03-2018; Accepted: 21-04-2018; Published online: 10-05-2018 